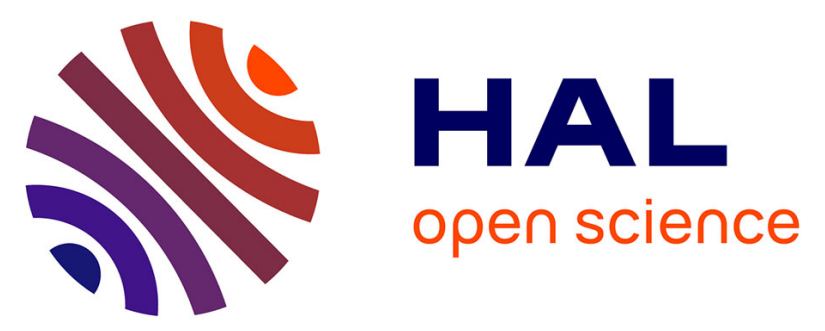

\title{
Hydroxyurea (HU) is effective in reducing JAK2V617F mutated clone size in the peripheral blood of essential thrombocythemia (ET) and polycythemia vera (PV) patients
}

Emmanouil Spanoudakis, Ioanna Bazdiara, Ioannis Kotsianidis, Dimitrios Margaritis, Aggelos Goutzouvelidis, Anna Christoforidou, Costas Tsatalas, George Bourikas

\section{- To cite this version:}

Emmanouil Spanoudakis, Ioanna Bazdiara, Ioannis Kotsianidis, Dimitrios Margaritis, Aggelos Goutzouvelidis, et al.. Hydroxyurea (HU) is effective in reducing JAK2V617F mutated clone size in the peripheral blood of essential thrombocythemia (ET) and polycythemia vera (PV) patients. Annals of Hematology, 2008, 88 (7), pp.629-632. 10.1007/s00277-008-0650-1 . hal-00535010

\author{
HAL Id: hal-00535010 \\ https://hal.science/hal-00535010
}

Submitted on 11 Nov 2010

HAL is a multi-disciplinary open access archive for the deposit and dissemination of scientific research documents, whether they are published or not. The documents may come from teaching and research institutions in France or abroad, or from public or private research centers.
L'archive ouverte pluridisciplinaire HAL, est destinée au dépôt et à la diffusion de documents scientifiques de niveau recherche, publiés ou non, émanant des établissements d'enseignement et de recherche français ou étrangers, des laboratoires publics ou privés. 


\title{
Hydroxyurea (HU) is effective in reducing JAK2V617F mutated clone size in the peripheral blood of essential thrombocythemia (ET) and polycythemia vera (PV) patients
}

\author{
Emmanouil Spanoudakis • Ioanna Bazdiara • \\ Ioannis Kotsianidis • Dimitrios Margaritis • \\ Aggelos Goutzouvelidis • Anna Christoforidou • \\ Costas Tsatalas • George Bourikas
}

Received: 9 September 2008 / Accepted: 13 November 2008 /Published online: 19 December 2008

(C) Springer-Verlag 2008

\begin{abstract}
Ph-negative chronic myeloproliferative disorders $\left(\mathrm{Ph}^{\text {neg }} \mathrm{cMPD}\right)$ are treated according to the estimated vascular risk. The recent discovery of $\mathrm{V} 617 \mathrm{~F}$ point mutation of the JAK2 kinase, which frequently occurs in these diseases, has not changed their management so far. However, emerging data tend to support a prothrombotic role for the mutation, along with a better response of JAK2V617F mutated patients to hydroxyurea treatment. Our data further support this notion.
\end{abstract}

Keywords $\mathrm{Ph}^{\text {neg }} \mathrm{cMPD} \cdot \mathrm{JAK} 2 \mathrm{~V} 617 \mathrm{~F} \cdot$ Hydroxyurea

\section{Introduction}

The introduction of JAK2V617F point mutation has undoubtedly simplified the diagnostic algorithm of Ph-negative chronic myeloproliferative disorders ( $\left.\mathrm{Ph}^{\text {neg }} \mathrm{cMPD}\right)$. However, no particular therapeutic intervention is at the moment based on JAK2V617F mutational status [1]. Awaiting the effect of JAK2 kinase inhibitors, treatment is mainly

Electronic supplementary material The online version of this article (doi:10.1007/s00277-008-0650-1) contains supplementary material, which is available to authorized users.

E. Spanoudakis · I. Bazdiara - I. Kotsianidis · D. Margaritis ·

A. Goutzouvelidis $\cdot$ A. Christoforidou $\cdot$ C. Tsatalas $(\square) \cdot$

G. Bourikas

Department of Haematology, Democritus University of Thrace,

Medical School,

Area of Dragana,

Alexandroupolis PC: 68100, Greece

e-mail: ktsatala@med.duth.gr administered to $\mathrm{Ph}^{\text {neg }} \mathrm{cMPD}$ patients predicted to have high vascular risk [2]. Risk factors include advanced age and thrombotic history while leucocytosis has recently been identified as an independent risk factor [3, 4]. Even though it is well established that JAK2V617F positive patients shows enhanced myelopoiesis $[5,6]$, the effect of JAK2V617F as a new thrombotic risk factor is still under investigation. Hydroxyurea (HU) is currently the cytoreductive treatment of choice, while interferon- $\alpha$ (IFN $\alpha)$ and anagrelide are preferred in selected cases. Accumulating evidence with this agent suggests that $\mathrm{HU}$ is an effective, well-tolerated, and probably safe agent for $\mathrm{Ph}^{\text {neg }} \mathrm{cMPD}$ treatment $[7,8]$.

Interestingly, $\mathrm{Ph}^{\text {neg }} \mathrm{cMPD}$ patients who carry the JAK2V617F mutation are more responsive to HU treatment and their disease can be controlled with lower drug doses [9]. The possibility of increased thrombotic risk in JAK2V617F positive patients in conjunction with the efficacy of HU treatment suggest its use upfront in this selected subgroup of $\mathrm{Ph}^{\text {neg }} \mathrm{cMPD}$ patients. Therefore, the aim of our study was to establish the efficacy of HU treatment in reducing the load of JAK2V617F mutated hematopoiesis.

\section{Materials and methods}

Patient samples

Peripheral blood samples from 12 essential thrombocythemia (ET) and six polycythemia vera (PV) patients, all positive for the JAK2V617F mutation, were obtained at diagnosis and thereafter at different time points, while 
Table 1 Patients characteristics

\begin{tabular}{|c|c|c|c|c|c|c|c|c|c|}
\hline \multirow[t]{2}{*}{ Patient } & \multicolumn{3}{|c|}{ Pretreatment } & \multirow{2}{*}{$\begin{array}{l}\text { HU } \\
\text { g/week }\end{array}$} & \multirow{2}{*}{$\begin{array}{l}\text { Time on HU } \\
\text { mo }\end{array}$} & \multicolumn{3}{|c|}{ Posttreatment } & \multirow{2}{*}{$\begin{array}{l}\text { Jak2 } \\
\text { V617F }\end{array}$} \\
\hline & $\mathrm{Ht} \%$ & WBC & Plt $10^{9} / \mathrm{L}$ & & & $\mathrm{Ht} \%$ & WBC & Plt $10^{9} / \mathrm{L}$ & \\
\hline ET 1 & 42.3 & 6.8 & 812 & 5 & 23 & 39 & 5.4 & 333 & Neg \\
\hline ET 2 & 41.8 & 6.7 & 691 & 6 & 18 & 41 & 7.2 & 411 & Pos \\
\hline ET 3 & 40 & 8.1 & 752 & 3 & 18 & 36 & 7.0 & 445 & $\mathrm{Neg}$ \\
\hline ET 4 & 47.6 & 10.7 & 584 & 3 & 7 & 35 & 10 & 110 & Pos \\
\hline ET 5 & 43.7 & 6.3 & 715 & 5 & 24 & 44 & 4.7 & 293 & Pos \\
\hline ET 6 & 43.5 & 10.6 & 698 & 10.5 & 30 & 41 & 8.0 & 453 & Pos \\
\hline ET 7 & 35 & 13.6 & 523 & 17.5 & 36 & 34 & 12 & 431 & Pos \\
\hline ET 8 & 48.6 & 12 & 594 & 10.5 & 20 & 44 & 5.3 & 361 & Pos \\
\hline ET 9 & 43 & 11.3 & 1.044 & 4.5 & 12 & 4. & 5.7 & 315 & Pos \\
\hline ET 10 & 40.5 & 15.4 & 1.653 & 5 & 24 & 34.6 & 4.3 & 252 & Pos \\
\hline ET 11 & 37.6 & 11 & 995 & 3 & 40 & 33.9 & 4.5 & 353 & Pos \\
\hline ET 12 & 42 & 9 & 785 & 7 & 28 & 44 & 3.7 & 322 & Pos \\
\hline Median & 42.5 & 10.62 & 733.5 & 5 & 23.5 & 39.5 & 5.55 & 343 & \\
\hline PV 1 & 62.2 & 9.4 & 218 & 5 & 8 & 39 & 6.2 & 226 & $\mathrm{Neg}$ \\
\hline PV 2 & 48 & 22 & 372 & 3.5 & 38 & 42 & 12.8 & 125 & Pos \\
\hline PV 3 & 48 & 31.6 & 1201 & 10.5 & 23 & 42 & 11 & 217 & Pos \\
\hline PV 4 & 69.2 & 10.2 & 838 & 7 & 18 & 46 & 5.2 & 345 & Pos \\
\hline PV 5 & 54.4 & 9.6 & 583 & 8 & 56 & 45.7 & 5.2 & 201 & Pos \\
\hline PV 6 & 58.4 & 7.6 & 369 & 7 & 56 & 45.7 & 5.2 & 201 & Pos \\
\hline Median & 56.4 & 9.9 & 477.5 & 7 & 30.5 & 42 & 7.1 & 221.5 & \\
\hline
\end{tabular}

ET essential thrombocythemia, PV polycythemia vera, $H U$ hydroxyurea, mo months on treatment, Neg negative for JAK2V617F in peripheral blood, Pos positive for JAK2V617F in the peripheral blood

receiving HU treatment. All of them were considered good responders to $\mathrm{HU}$ treatment based on clinical criteria $(\mathrm{Ht}<$ $45 \%$ for PV and Plts $<400 \times 10^{9} / \mathrm{L}$ for ET patients) [10]. Individual patient's pre- and posttreatment peripheral blood counts, along with HU dose administered and time on treatment, are presented in Table 1. This study was approved by the local ethics committee.
Allele-specific polymerase chain reaction (ASO-PCR) method for JAK2V617F mutation detection

For JAKV617F detection, the method described by Baxter et al. was used. Briefly, genomic DNA was extracted from $350 \mu \mathrm{l}$ of whole blood (QIAgen EZ1 Biorobot). ASO-PCR was performed by using $100 \mathrm{ng}$ of genomic DNA and the

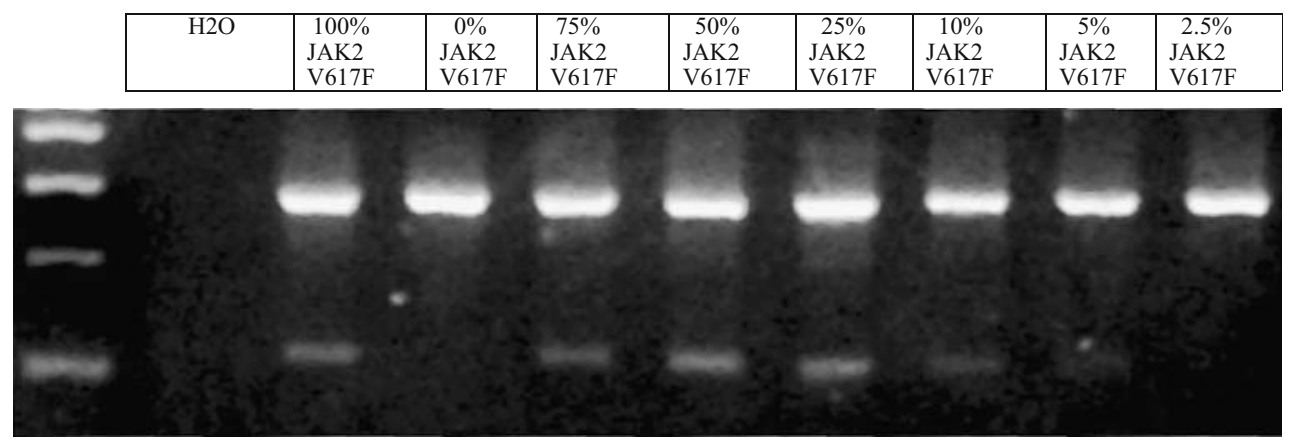

Fig. 1 Sensitivity of ASO-PCR method to detect JAK2V617F mutated clones in peripheral blood samples: A peripheral blood sample from a homozygous for JAK2V617F mutation polycythemia vera patient was obtained and subjected to double gradient FicollHistopaque separation in order to select granulocytes. The same procedure was followed and in a peripheral blood sample from a normal donor (ND). Cells were counted and resuspended in medium to the final concentration of 1 million cells per ml. Then we mixed proper amounts of PV- and ND-derived cell suspensions in order to have mixed samples with controlled percentages of JAK2V617F mutated clones ranging from $100 \%$ to $2.5 \%$. Cells were then spun down, supernatant was removed, and genomic DNA was extracted. Following the method we describe at the "Materials and method" section, we performed ASO-PCR for JAK2V617F mutation detection and the method was proved to have a sensitivity between $2.5 \%$ and $5 \%$ 
Fig. 2 Hydroxyurea treatment reduce to undetectable levels the JAK2V617F clone size in the peripheral blood $(P B)$ of two essential thrombocythemia patients (ET1 and ET3) and a polycythemia vera patient $(P V 1)$ but not in bone marrow $(B M)$ samples from the same patients. a Allele-specific PCR. b BsaXI enzyme restriction analysis. c Purity of CD34+ cells after positive selection with immunomagnetic beads (MiniMACS, Miltenyi Biotec) from the bone marrow of patients ET3 and PV1 that both show sustained peripheral blood negativity for JAK2V617F mutated clones. d Results of JAK2V617F detection on CD34+ selected hematopoietic progenitors by using the ASO-PCR method. In both patients, mutated clones were detectable a)

\begin{tabular}{|l|l|l|l|l|l|l|l|l|}
\hline lader & Neg & Pos & $\begin{array}{l}\text { ET1 } \\
\text { PB }\end{array}$ & $\begin{array}{l}\text { ET1 } \\
\text { BM }\end{array}$ & $\begin{array}{l}\text { ET3 } \\
\text { PB }\end{array}$ & $\begin{array}{l}\text { ET3 } \\
\text { BM }\end{array}$ & $\begin{array}{l}\text { PV1 } \\
\text { PB }\end{array}$ & $\begin{array}{l}\text { PV1 } \\
\text { BM }\end{array}$ \\
\hline
\end{tabular}

b)

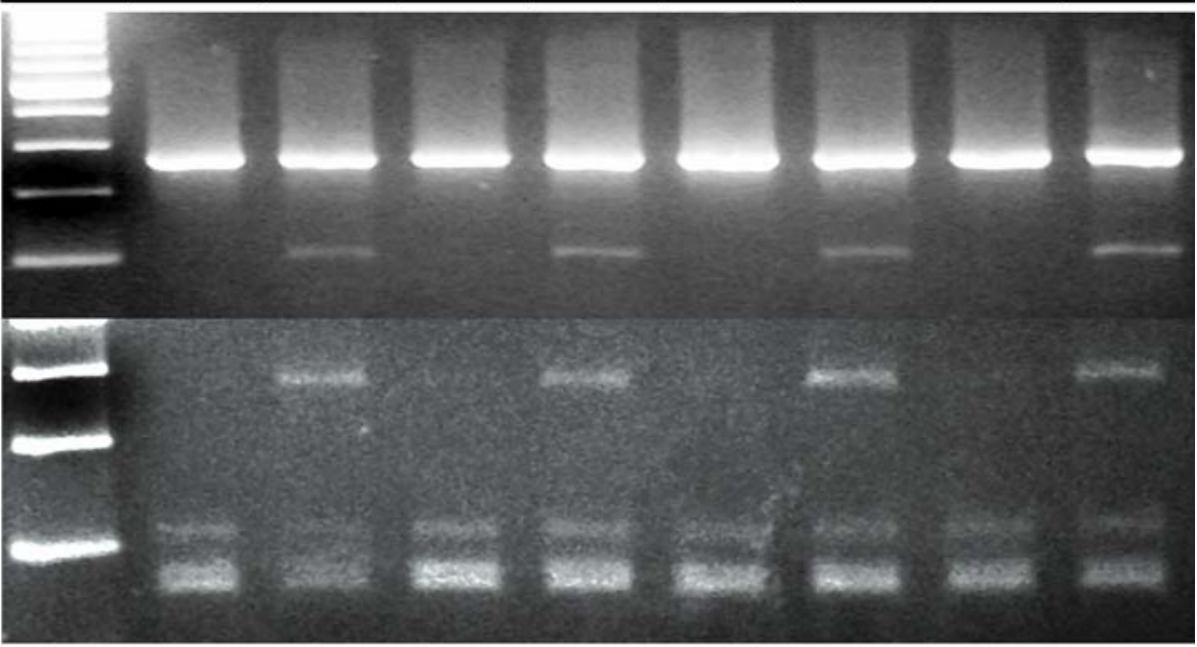

c)

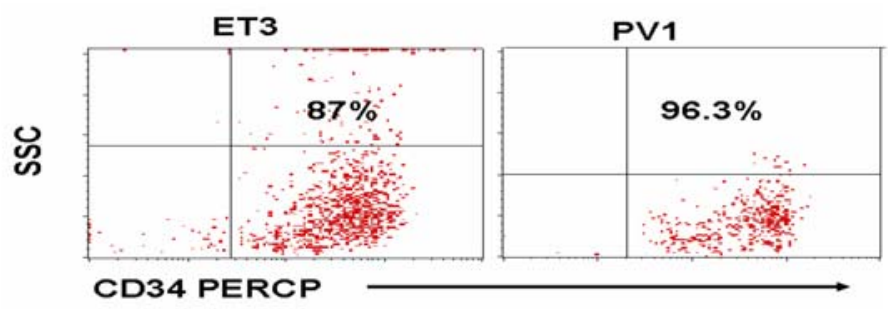

d)

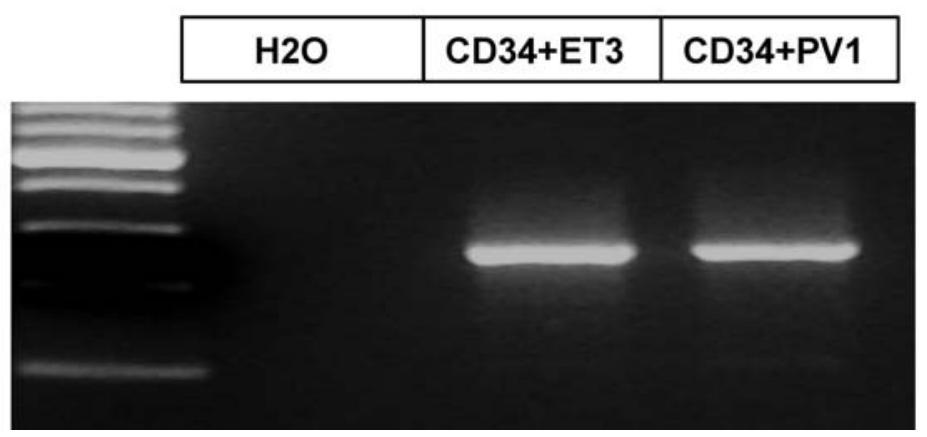

following set of primers were used (OPERON, Cologne, Germany):

\section{R JAK2: 5'CTGAATAGTCCTACAGTGTTTTCA GTTTCA3 \\ F WT: 5'AGCATTTGGTTTTAAATTATGGAGTA TATT3' \\ F V617 F: 5'ATCTATAGTCATGCTGAAAGTAGGA GAAAG3'}

PCR conditions were denaturation $95^{\circ} \mathrm{C}$ for $5 \mathrm{~min}$ followed by 35 cycles of amplification with denaturation $95^{\circ} \mathrm{C}$ for $30 \mathrm{~s}$, annealing $58^{\circ} \mathrm{C}$ for $30 \mathrm{~s}$, elongation $72^{\circ} \mathrm{C}$ for $1 \mathrm{~min}$, and finally $5 \mathrm{~min}$ of elongation at $72^{\circ} \mathrm{C}$. Then $10 \mu \mathrm{l}$ of PCR product were subjected to $1.5 \%$ agarose gel electrophoresis and the bands were detected under UV light using ethidium bromide as detection agent. Unmutated JAK2 samples produce a band of $364 \mathrm{bp}$ and the mutated samples an extra band of 203 bps. In our hands, the sensitivity of the method to detect JAK2V617F mutated clones in peripheral blood samples is between $2.5 \%$ and $5 \%$ as described in Fig. 1 and linearity between JAK2V617F concentration and band width is better at low concentration levels.

\section{BsaXI restriction analysis}

A PCR reaction by using R JAK2 and F WT primes was performed as described above. Twenty microliters of PCR product were then subjected to digestion with $1 \mathrm{IU}$ of BsaXI in a water bath settled at $37^{\circ} \mathrm{C}$ after overnight 
incubation. Afterwards, samples were subjected to agarose gel electrophoresis.

\section{Results and discussion}

Regarding ET patients, median duration of HU treatment was 23.5 months (range 7-40 months), median HU dose was $5 \mathrm{~g} /$ week (3-17.5), and median platelet count at time of JAK2V617F detection was $343 \times 10^{9} / \mathrm{L}(110-445)$. PV patients received $7 \mathrm{~g}$ /week $\mathrm{HU}(3.5-10.5)$ for a median period of 30.5 months $(8-56)$ and the median $\mathrm{Ht}$ values were $42 \%(36-46 \%)$.

In this cohort where all patients approach the therapeutic goal of HU treatment, JAK2V617F mutation status and allele burden were assessed as described above. In two of twelve ET patients and in one of six PV patients, JAK2V617F mutated clones could not be detected on peripheral blood samples by both ASO-PCR and BsaXI enzyme restriction analysis (Fig. 2a, b). All three negative samples came from patients heterozygous for the JAK2V617F mutation. In order to enforce our data, we obtained a second sample from these three patients, 3 months after the detection of the first negative for the JAK2V617F mutation sample. We found out that in two out of three patients, the response was sustained (Supplementary Figure 1A). In contrast, the third patient lost JAK2V617F negativity in the peripheral blood, presumably because of transient HU discontinuation (2 weeks) after prolonged hospitalization due to a major surgery, thus suggesting the need for continuous HU administration. However, bone marrow samples obtained after the peripheral blood became negative for the JAK2V617 mutation were still positive for the mutation (Fig. 2a, b). In addition, we found that even after 3 months of sustained peripheral blood negativity, we were still able to detect JAK2V617 positive clones in the bone marrow (Supplementary Figure 1B). Interestingly, the fraction of highly purified CD34+ bone marrow derived hematopoietic progenitors also contained mutated clones, but they represented a small subset of these progenitors (Figs. 2c, d).

In conclusion, $\mathrm{HU}$ can induce a sustained reduction or even eradication of the JAK2V617F clone size in the peripheral blood of $\mathrm{Ph}^{\text {neg }} \mathrm{cMPD}$ patients. However, this effect should not be considered as an evidence of a major molecular response, since the clone exists in the bone marrow and in selected CD34+ hematopoietic progenitor cells. Nevertheless, it is suggestive of an effective treatment that might be proved of clinical benefit, especially considering the correlation between JAK2V617F allele burden and overall vascular risk [11]. Our results are in accord with two recent studies that proved the efficacy of HU treatment in reducing the copies of JAK2V617 in the peripheral blood of $\mathrm{Ph}^{\text {neg }} \mathrm{cMPD}$ patients $[12,13]$. Thus, although not as effective as IFN $\alpha$ [14], HU has considerable efficacy against JAK2 mutated hematopoietic clones.

\section{References}

1. Tefferi A (2006) Classification, diagnosis and management of myeloproliferative disorders in the JAK2V617F era. Hematology Am Soc Hematol Educ Program 2006:240-245

2. Birgegård $\mathrm{G}$ (2008) Long-term management of thrombocytosis in essential thrombocythaemia, Ann Hematol (in press), Jul 16

3. Carobbio A, Finazzi G, Guerini V, Spinelli O, Delaini F, Marchioli R, Borrelli G, Rambaldi A, Barbui T (2007) Leukocytosis is a risk factor for thrombosis in essential thrombocythemia: interaction with treatment, standard risk factors, and Jak2 mutation status. Blood 109:2310-2313 doi:10.1182/blood-2006-09-046342

4. Landolfi R, Di Gennaro L, Barbui T, De Stefano V, Finazzi G, Marfisi R, Tognoni G, Marchioli R (2007) Leukocytosis as a major thrombotic risk factor in patients with polycythemia vera. Blood 109:2446-2452

5. Spanoudakis E, Margaritis D, Kotsianidis I, Georgiou G, Tripsianis G, Anastasiadis A, Karakolios A, Pantelidou D, Panayiotidis P, Bourikas G, Tsatalas C (2008) Long-term bone marrow cultures (LTBMC) from essential thrombocythemia (ET) patients with or without JAK2617V >F mutation. Leuk Res 32:1593-1596

6. Campbell PJ, Scott LM, Buck G, Wheatley K, East CL, Marsden JT, Duffy A, Boyd EM, Bench AJ, Scott MA, Vassiliou GS, Milligan DW, Smith SR, Erber WN, Bareford D, Wilkins BS, Reilly JT, Harrison CN, Green AR (2005) Definition of subtypes of essential thrombocythaemia and relation to polycythaemia vera based on JAK2 V617F mutation status: a prospective study. Lancet 366:1945-1953

7. Harrison CN, Campbell PJ, Buck G, Wheatley K, East CL, Bareford D, Wilkins BS, van der Walt JD, Reilly JT, Grigg AP, Revell P, Woodcock BE, Green AR (2005) Hydroxyurea compared with anagrelide in high-risk essential thrombocythemia. N Engl J Med 353:33-45

8. Gangat N, Tefferi A (2008) Pharmacotherapy of essential thrombocythemia. Expert Opin Pharmacother 9:1679-1685

9. Sirhan S, Lasho TL, Hanson CA, Mesa RA, Pardanani A, Tefferi A (2008) The presence of JAK2V617F in primary myelofibrosis or its allele burden in polycythemia vera predicts chemosensitivity to hydroxyurea. Am J Hematol 83:363-365

10. Finazzi G, Barboui $T$ (2008) Evidence and expertise in the management of polycythemia vera and essential thrombocythemia. Leukemia 22:1494-1502

11. Kittur J, Knudson RA, Lasho TL, Finke CM, Gangat N, Wolanskyj AP, Li CY, Wu W, Ketterling RP, Pardanani A, Tefferi A (2007) Clinical correlates of JAK2V617F allele burden in essential thrombocythemia. Cancer 109:2279-2284

12. Ricksten A, Palmqvist L, Johansson P, Andreasson B (2008) Rapid decline of JAK2V617F levels during hydroxyurea treatment in patients with polycythemia vera and essential thrombocythemia. Haematologica 93:1260-1261

13. Girodon F, Schaeffer C, Cleyrat C, Mounier M, Lafont I, Dos santos F, Vidal A, Maynadié M, Hermouet S (2008) Frequent reduction or absence of detection of the JAK2-mutated clone in JAK2V617F-positive patients within the first years of hydroxyurea therapy. Haematologica 93:1723-1727

14. Kiladjian JJ, Cassinat B, Chevret S, Turlure P, Cambier N, Roussel M, Bellucci S, Grandchamp B, Chomienne C, Fenaux P (2008) Pegylated interferon-alfa-2a induces complete hematological and molecular responses with low toxicity in polycythemia vera. Blood 112:3065-3072 